\title{
Good practices for the prevention of alcohol harmful use amongst the elderly in Europe, the VINTAGE project
}

\author{
Jorge Palacio-Vieira ${ }^{(a)}$, Lidia Segura ${ }^{(a)}$, Antoni Gual ${ }^{(b)}$, Joan Colom ${ }^{(a)}$, Salme Ahlström ${ }^{(\mathrm{c})}$, \\ Sandra Radoš Krnel ${ }^{(\mathrm{d})}$, Andrew McNeill ${ }^{(\mathrm{e})}$, Hana Sovinova ${ }^{(\mathrm{f})}$ and Emanuele Scafato ${ }^{(\mathrm{g})}$ \\ for the VINTAGE project Working Group* \\ ${ }^{(a)}$ Department of Health, Program on Substance Abuse, Generalitat de Catalunya, Barcelona, Spain \\ (b) Alcohology Unit, Hospital Clinic, Barcelona, Spain \\ (c) National Institute for Health and Welfare, Helsinki, Finland \\ ${ }^{(d)}$ Research Centre, Institute of Public Health, Ljubljana, Slovenia \\ ${ }^{(e)}$ Institute of Alcohol Studies, Huntingdon, United Kingdom \\ (f) Coordination, Monitoring and Research Unit, National Institute of Public Health, Praha, Czech Republic

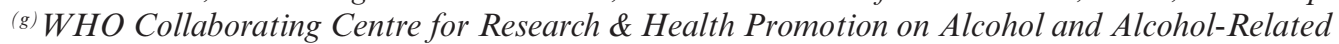 \\ Health Problems, Osservatorio Nazionale Alcol, Centro Nazionale di Epidemiologia, Sorveglianza e \\ Promozione della Salute, Istituto Superiore di Sanità, Rome, Italy \\ *see Appendix
}

\begin{abstract}
Introduction. There is a lack of information about initiatives aimed at preventing the harmful effects of alcohol amongst the elderly. Objectives. One of the objectives of the VINTAGE study was to collect the initiatives carried out in Europe and review the published grey literature about this topic. Methods. Email-based survey addressed to researchers, professionals and policymakers, and internet search of grey literature. Results. Three hundred nine contacts were finally made, and 21 of the 36 collected initiatives were considered as useful in preventing the harmful use of alcohol amongst the elderly. Out of the about 2900 references identified 96 were classified as relevant. Conclusions. Despite a growing interest, alcohol use in the elderly is not yet perceived as a major issue for prevention.
\end{abstract}

Key words: aged, alcohol drinking, promotion, prevention, Europe.

Riassunto (Esempi di buona pratica per la prevenzione del consumo dannoso di alcol negli anziani in Europa, il progetto VINTAGE). Introduzione. C'è carenza di informazioni sulle iniziative volte a prevenire gli effetti dannosi del consumo di alcol tra gli anziani. Obiettivi. Uno degli obiettivi dello studio VINTAGE è stato quello di raccogliere esempi di intervento condotti in Europa ed eseguire una revisione della letteratura grigia sull'argomento. Metodi. Indagine via e-mail, rivolta a ricercatori, professionisti e decisori politici, e revisione della letteratura grigia disponibile in Internet. Risultati. Su 309 contatti effettuati, 21 delle 36 iniziative raccolte sono state ritenute utili per la prevenzione del consumo dannoso di alcol tra gli anziani. Novantasei dei circa 2900 riferimenti bibliografici individuati sono stati classificati rilevanti. Conclusioni. Nonostante un crescente interesse, il consumo di alcol tra gli anziani non è ancora percepito come obiettivo prioritario di prevenzione.

Parole chiave: anziano, assunzioni di alcoolici, promozione, prevenzione, Europa.

\section{INTRODUCTION}

Three major trends are changing the demographic structure in Europe: continuing increases in longevity, the growth in the number of workers over 60 years of age and continuing low birth rates. The structure of society is also changing radically. Families are characterized by "older workers" (55$64)$, elderly people (65-79) and very elderly people $(80+)$, fewer children, young people and adults of working age [1]. Some strategies have been imple- mented to deal with this trend. The Commission of the European Communities has signaled health policies as one of the challenges for the European countries. One of these strategies states that the Commission will give special attention to medical and social research related to ageing, covering a wide range of research activities including basic, medical, technological and social research; and support the Member States in their efforts to develop adequate responses to ageing in health and 
care through studies of how different systems are working [2].

The use of alcohol is the third-leading risk factor for death and disability in Europe [3]. Amongst the elderly population the use of alcohol has been associated to a wide number of physical and psychological disorders and according to some authors it could be responsible for $12 \%$ of premature death and disability among males and 2\% among females [4]. The European report on alcohol consumption among the elderly described a decreased trend in alcohol abstinence amongst elderly Europeans; an increasingly heavy drinking resulting in higher death rates and more hospitalizations (mainly males); the relationship between the total volume of alcohol consumed and alcohol-related harm; heterogeneity in the alcohol consumption by age group and the lack of alcohol consumptions guidelines for elderly [5]. Combining the demographic trend and estimations of alcohol consumption, researchers in United States described an increasing number of elderly persons with alcohol-related problems and predicted around 3.5 millions of alcoholic people by 2030 (prevalence of $5 \%$ of the population of 60 years or older) [6].

According to some authors alcohol consumption by the elderly is a subject which has until recently fallen between the gaps of ageing research on the one hand, and alcohol and drug research and policy on the other [7]. These authors mentioned that research should consider the circumstances under which elderly people use alcohol, the psychosocial benefits of moderate drinking and the health risks associated with hazardous consumption. In this sense, an accurate revision of scientific studies published in 2003 showed that alcohol use disorders in elderly people are common and are associated with notable health problems, the ageing of populations worldwide means that the absolute number of older people with alcohol use disorders is on the increase. Alcohol use disorders are underdetected and misdiagnosed for various reasons, they are associated with notable impairments in general health, inpatient detoxification is recommended for elderly people, information on the use of abstinence medications in elderly people is limited, alcohol treatment for elderly people may be more appropriate among their peers and recommended limits for intake, screening instruments, and diagnostic criteria must be redefined for elderly people [8].

Although prioritizing on the development and implementation of effective measures in primary and elderly health care and reducing the negative impact of drinking in terms of alcohol-related mortality, morbidity and disability has been one of the strategies of the Council of the European Union [9] little is known about initiatives already implemented in Europe addressed exclusively to prevention of the harmful use of alcohol.

The VINTAGE study, funded by the European
Commission under the $2^{\text {nd }}$ Programme of Community Action in the Field of Health (20082013) was aimed to build capacity at the European, country and local levels by providing the evidence base and collecting best practices to prevent the harmful use of alcohol amongst older people, including the transition from work to retirement. In addition, this project was also aimed at providing policy makers with cost-effectiveness and cost-efficiency studies in order to develop appropriate ageoriented alcohol policies; to generate financial support for comparative research across countries; to renew and support a policy making culture based on research; and to commence a formal alcohol policy evaluation to determine the effectiveness and the sustainability of different policy options [10].

The objective of this article is to describe best practices (BP) collected across Europe to prevent the harmful use of alcohol among the elderly and summarize the grey literature about alcohol-related harm in elder drinkers.

\section{METHODS}

The present work is part of the VINTAGE - Good Health into Older Age that has been previously described in detail in this monographic issue.

The VINTAGE project lasted 21 months, from March 2009 to November 2010, and was coordinated by the Istituto Superiore di Sanità (ISS, Italy) involving a network led by key centres in Europe. One of the five strategies carried out in the VINTAGE project, work package five (WP5), sought to collect examples of good practices and effective policies and programmes and review grey literature for the prevention of the harmful use of alcohol amongst the elderly.

Firstly, an email-based survey, coordinated by the Government of Catalonia (GENCAT), was carried out to contact professionals and researchers all around Europe. An ad hoc questionnaire was sent to potential participants by the five WP5 partners, who were responsible for reaching experts from the following geographic areas: GENCAT, Mediterranean countries; National Institute for Health and Welfare (THL, Finland), Nordic and Baltic countries; Institute of Alcohol Studies (IAS, United Kingdom), Continental countries and UK; National Institute of Public Health (IVZ, Slovenia), South-east Europe and Balkans; and National Institute of Public Health (SZU, Czech Republic), Central Europe countries.

The survey followed a strategy previously applied in similar European studies [11]. In addition, the questionnaire was also circulated among members of some networks like Alcohol Policy Network (APN), National Counterparts for Alcohol Policy in the WHO European Region, Primary Health Care European Project on Alcohol(PHEPA), International Network of Brief Interventions for Alcohol Problems (INEBRIA) and EUROCARE. The questionnaire was structured as follows: 
- brief description of the study, its objectives and methods and the instructions for completing the questionnaire including definitions and criteria;

- contact data of compiler: name, email and country;

- for those not reporting any BP, a "negative" brief module was included with a 4-point Likert scale from "4" (more important) to " 1 " (less important). It consisted in five short statements about the reasons of the lack of BP to be scored;

- for those reporting a BP (positive), a list of questions was asked grouped in 6 components addressing mainly the following issues:

- basic facts: name, type of BP and aims and objectives;

- development: background, origin, main components and target. Implementation: funding, level of implementation, starting date, duration and main results;

- evaluation: how, when type of evaluation, preconditions for success, obstacles, harmful effects and main lessons learned;

- extra details: website and contact information and references;

- final comments and suggestions.

Secondly, grey literature (www.opengrey.eu/about/ greyliterature) was collected by means of internetbased and structured searches using the following terminology: "alcohol", "alcoholism", "alcohol use disorders", "hazardous alcohol use", "harmful alcohol use", "alcohol abuse", "alcohol misuse", "alcohol withdrawal", "elderly", "healthy aging", "morbidity and mortality", "geriatrics", "elder care" and "gerontology", "alcohol rehabilitation", "prevention", "intervention".

Terms were systematically entered into well-known sources of grey literature and Internet-based databases and meta-searchers. Combinations of terms and keywords were carried out in order to avoid loss of information. However given that each source of information had its particular search methodology it was not possible to use a homogenous plan of search.

Specific terminology and keywords, and several combinations between them were used (operated by means of "and", "or", "not"). In some cases sources of information allowed to filter results by date, subject, country and other parameters.

\section{Analysis}

Responses to the questionnaire were blindly assessed and the inclusion of any initiative and its consideration as a BP was conditioned by fulfilment of the following criteria: addressed only to alcohol, designed for older people (or adapted to their needs) evaluated or under evaluation, a clear definition of its objectives, covering phases from design and implementation to analysis and presentation of results. In a second step, the quality of the collected examples was evaluated according to an explicit statement of the following criteria:
- needs assessment: if a pre-evaluation was carried out before developing the project. The needs assessment had to be done before the design and implementation of the plan and covered specifically older people;

- accessibility: if the program was widely and easily accessible for older people;

- setting approach: it could be any specific geographic area (city, region or country) or a clinical setting. Participants were asked to specify the setting approach where their program was carried out and how the population could take part in it;

- collaborative capacity/partnership: level of participation from different partners, centres and professionals or the existence of collaborative alliances among institutions;

- evaluation: type of evaluation developed to control the quality of the program from its design to the implementation phase;

- sustainability: availability of resources to sustain the initiative over the years;

- transferability: the possibility of transferring the program to other settings and how the program developed assets which could be helpful for people;

- availability of results: existence of documents, papers and reports in both white and grey literature;

- transparency of funding/support: if the source of funding and support was public and transparent.

Four criteria were used to analyse interventions described in grey literature publications:

- to be specifically designed for the elderly;

- its objectives and strategies had to follow scientific evidence;

- it should have been implemented in a population, sample or group of old people;

- to be assessed and controlled by means of quality criteria.

Only reported initiatives that fulfilled at least one of them were considered as good practices for the prevention of the harmful use of alcohol among the elderly.

\section{RESULTS}

A total of 309 professionals and researchers from 40 countries and European institutions were contacted reporting 53 negative and 36 positive initiatives addressed to prevent the harmful use of alcohol amongst the elderly (Figure 1). Participants were mainly from governmental institutions $(\mathrm{n}=$ $133,43 \%)$, followed by research institutions $(\mathrm{n}=90$, $29 \%)$, nongovernmental organizations $(n=65,21 \%)$ and other centres $(\mathrm{n}=21,7 \%)$.

Table 1 shows the mean response to the 5 questions about the reasons for the absence of any existing good practice to describe (negative responses to the questionnaire). Scores ranged from " 4 " 

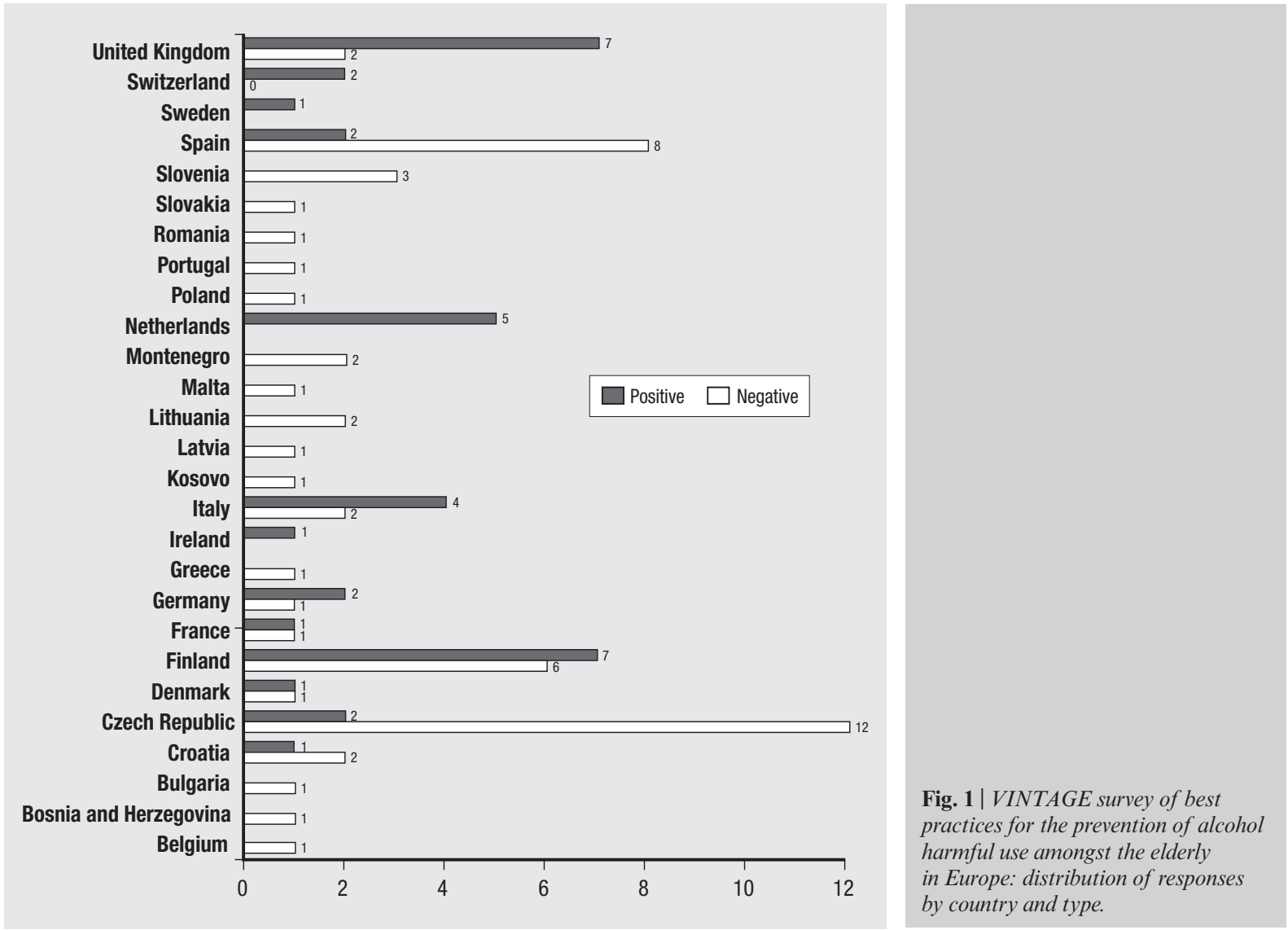

(most important) to "1" (least important), a high score means a high perception of the participants about the importance of such factor on the absence of best practices in their country. According to participants' responses, the "lack of public health policies on elderly addressing prevention strategies on alcohol consumption and related problems" is the leading cause of the absence of BP (mean score 3.36). In contrast, the perception that "it's too late to do anything" was considered as the least important cause of the absence of BP (mean score 2.12).

After being analysed 21 out of the 36 reported initiatives $(58 \%)$ met the best practice criteria $(5$ from Finland and Italy, 4 from Netherlands and UK, 2 from Germany and 1 from Spain). Some initiatives were excluded because of the lack of a proper definition of the target group $(n=5,14 \%)$, were not addressed exclusively to alcohol issues (n $=4,11 \%$ ) and due to the absence of evaluation at any point of the programme $(n=6,17 \%)$. Figure 2 shows the inclusion and exclusion criteria used to assess all reported initiatives. In summary, most of the 21 reported initiatives for the prevention of harmful use of alcohol implemented in Europe were projects $(\mathrm{n}=12,57 \%)$, addressed exclusively to the elderly $(\mathrm{n}=13,62 \%)$, funded by the government $(\mathrm{n}=10,47 \%)$ and implemented at national

Table $1 \mid$ VINTAGE survey of best practices for the prevention of alcohol harmful use amongst the elderly in Europe: reasons for the absence of projects, programs or best practices as scored by participants providing negative response to the questionnaire

\section{Factor}



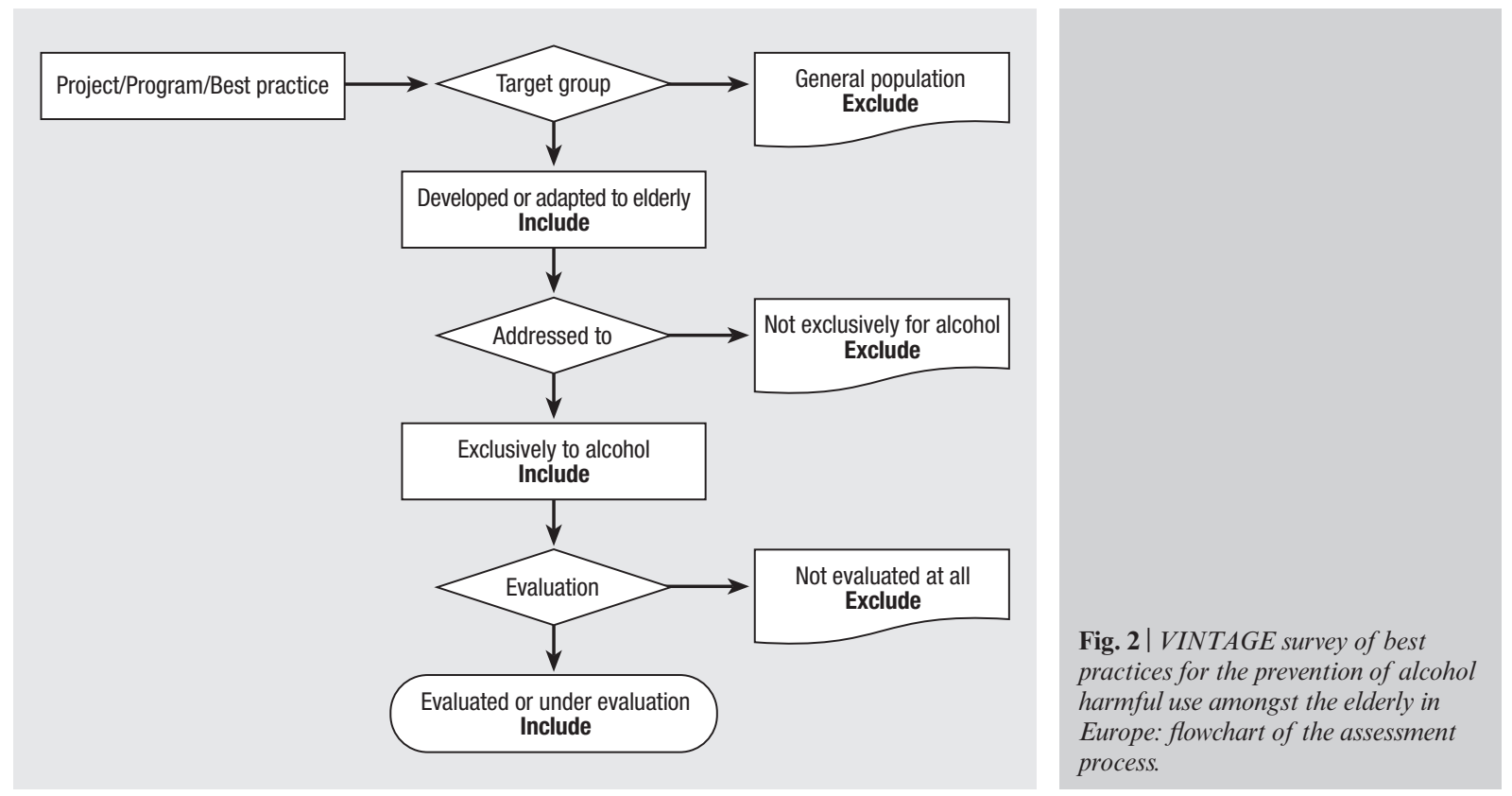

level $(\mathrm{n}=8,38 \%)$. Regarding their main elements the most common issues covered were: prevention/ early intervention, raising awareness, social and community support $(\mathrm{n}=15,71 \%)$, other elements such as personnel training $(\mathrm{n}=2,9.5 \%)$ elder care $(\mathrm{n}=2,9.5 \%)$, treatment $(\mathrm{n}=1,5 \%)$ and needs assessment $(\mathrm{n}=1,5 \%)$ were less common. Table 2 shows the distribution of collected best practices by main categories of classification. Table 3 shows selected initiatives by their source of funding and level of implementation respectively. Full and accessible information on the collected examples of best practices is available from an online database (http://vintage.saveva.com).

As reported by the participants the most relevant preconditions for success were professional empowerment, the direct and active participation of the people affected, collaboration between different partners, the support of governmental and academic institutions and a clear and constant communication during the whole process. Fourteen participants reported obstacles during the imple- mentation of initiatives, among them, delayed implementation due to changes in the organizational structure, lack of an effective and wider communication strategy, absence of support at the management and professional level, time limitation, the absence of networking strategies and discontinuation in the financial support. As regards suggested strategies to improve their initiatives, the following were reported: having extra funding to contract more professionals, working in networks and creating research-groups and models. Better communication, dissemination, partnership and integration strategies were also reported as areas of improvement.

Information on grey literature was found on 21 different websites and included 96 documents. However, despite the vast number of information, none of the documents found fulfilled all the criteria established to be considered as a best practice. According to their main topic or field of interest we found that grey literature is mainly focused on raising awareness $(n=24,25 \%)$ or social reinsertion/

Table 2 | VINTAGE survey of best practices for the prevention of alcohol harmful use amongst the elderly in Europe: classification of reported initiatives according to their main elements

\section{Main element}

Prevention/early intervention, raising awareness, social and community support

Personnel training

Elder care

Needs assessment

Treatment provision
Number (\%)

$15(71 \%)$

$1(5 \%)$
Table 3 | VINTAGE survey of best practices for the prevention of alcohol harmful use amongst the elderly in Europe: classification of reported initiatives by source of funding and level of implementation

\begin{tabular}{lccc|}
$\begin{array}{l}\text { Source of } \\
\text { funding }\end{array}$ & $\begin{array}{c}\text { Number } \\
(\%)\end{array}$ & $\begin{array}{c}\text { Level of } \\
\text { implementation }\end{array}$ & $\begin{array}{c}\text { Number } \\
\text { (\%) }\end{array}$ \\
\hline Government & $10(47 \%)$ & Clinical settings & $2(9 \%)$ \\
Private sector & $1(5 \%)$ & Local & $5(24 \%)$ \\
Research body & $5(24 \%)$ & National & $8(38 \%)$ \\
Other sources & $5(24 \%)$ & Regional & $4(19 \%)$ \\
& & Other & $2(10 \%)$
\end{tabular}


harm reduction $(\mathrm{n}=24,25 \%)$, followed by prevention/early intervention $(\mathrm{n}=18,19 \%)$, treatment $(\mathrm{n}$ $=10,10 \%)$, personnel training $(\mathrm{n}=5,5 \%)$, needs assessment ( $\mathrm{n}=7,7 \%)$, elder care/social and community support $(\mathrm{n}=8,9 \%)$. Another freely accessible online database was developed to store data deriving from results of the grey literature review (www.saveva.com/vintage_articles/default.aspx).

\section{DISCUSSION}

European professionals showed increasing interest in preventing harmful use of alcohol. However, there is a lack of standards to develop, implement and assess the efficacy of initiatives as well as a lack of long-lasting initiatives which include professional training, needs assessment and a balanced provision of treatment. The VINTAGE study evidenced that there is a growing public awareness about the effects of drinking at old age, showing an increasing interest in the effects of harmful drinking among this group and specific initiatives that have been carried out all around Europe, under different circumstances and with promising results. The implementation of new programmes for the prevention of the harmful use of alcohol are needed and will hopefully meet the special needs of the elderly and the diversity of factors affecting this group of population also taking into account the need for a gender approach. However, as other authors have reported [5] it is recommended that efforts be made to assess the feasibility and appropriateness of instruments to be used among elderly population.

Grey literature is a helpful source of information and should reach professionals, researchers, policy makers, students and interested people. However, exhaustive revisions should be properly carried out and published. Regarding the assessment of alcohol-related problems amongst the elderly, its screening and management, other authors have also reviewed the most relevant literature. Some of them have provided accurate overviews of the alcohol use, prevalence of drinking and best practices in assessment and psychological treatment [12] and in concordance with the evidence found in grey literature by the VINTAGE study these authors noted age-appropriate psychological treatment interventions that include brief interventions, family interventions, motivational counselling, and cognitive behavioural therapies.

Although our results are restricted only to grey literature, we have found information on positive and negative alcohol-related health effects in the group of elderly, a fact also suggested in a systematic review published by Reid MC et al. [13]. According to these authors the magnitude of risk posed by alcohol use on the morbidity and mortality of older adults is still uncertain. Grey literature reflects to some extent the growing body of literature and in- formation on alcohol-related problems amongst the elderly and provides a complement to other types of information on this field.

A large amount of grey literature was addressed to raising awareness on the alcohol consumption patterns amongst the elderly, followed by the impact of alcohol consumption on the health of elderly and the provision of evidence on the efficacy of early detection. The high number of publications on social reinsertion and harm reduction might also reflect the increasing need to adequately deal with the elderly affected by alcohol related problems, mainly those at risk of physical (i.e. bone density) and mental conditions (i.e. Dementia and Alzheimer disease). It is also important to highlight the relevance given in these studies to the risks of stigma and social exclusion among elderly.

Among the most common references found in the grey literature review were those regarding prevention and early interventions. It is vital to highlight the importance of studying the use of medication among the elderly and the potential risk of the concomitant use of alcohol for their physical and psychological well-being. The concomitant use of alcohol and some types of medications amongst the elderly was analysed by Moore AA et al. [14], concluding that it poses a variety of adverse consequences depending on the amount of alcohol and the type of medications consumed. In fact, these authors recommended exploring alcohol and medications together with counselling the elderly about their safe use. In our study counselling strategies were categorised as prevention and early intervention. In addition, this category includes many publications addressed to identification, screening, assessment, intervention, treatment and other issues related with elder drinkers. The existence of these types of publications was reviewed and reported as very important, given their role in raising the awareness among clinicians as well as in identifying and addressing alcohol abuse issues in the older adult population [15].

Results of the vintage study should be interpreted in the light of some limitations. Firstly, participants in the study were contacted through university, professionals and governmental networks and it was impossible to know if there was any best practice implemented outside of those networks. However, according to our knowledge most of the professionals and researchers interested in preventing alcohol harmful use are part of one (or even more) of those networks, in addition, in order to improve the dissemination of the survey, all participants were asked to inform if any of their colleagues could be interested in the study. Second, the use of a well-established methodology to collect grey literature does not ensure its accuracy and reproducibility. However, the use of local, European and international grey-literature databases could have improved the quality of the information collected. Finally, grey literature searches were restricted to the English language. 


\section{CONCLUSIONS}

The VINTAGE study is the first study addressed to collect and analyse best practices for the prevention of the harmful use of alcohol amongst the elderly population in Europe and its results should be incorporated in the design, implementation and assessment of any new initiative addressed to prevent the harmful use of alcohol amongst the elderly in Europe. When taking into account both sources of information, it can be concluded that:

- the implementation of new programmes for the prevention of the harmful use of alcohol are needed and will hopefully meet the special needs of the elderly and the diversity of factors affecting this group of population also taking into account the need for a gender approach;

- screening and intervention techniques are increasingly available at research level but still lack integrating the related instruments into daily practice and specific initiatives;

- there is an overall lack of evidence and initiatives to support the elderly with alcohol related problems and diseases by means of community level initiatives;

- public awareness about the effects of drinking at old age is growing even if a critical mass supporting higher levels of awareness and public health activation has to be achieved. Nonetheless, there is not only an increasing amount of literature on drinking in the elderly but also some relevant, specific initiatives that have been carried out with promising results;

- the increasing interest in the publication of grey literature seems to adequately respond to the changing demographical context and its complexity;

- although the objective of our study was to identify grey literature, comparisons of our results is consistent with systematic reviews published by other means.

\section{References}

1. Commission of the European Communities. Green Paper: Confronting demographic change: a new solidarity between the generations. Brussels: Commission of the European Communities; 2005. COM (2005) 94.

2. Commission of the European Communities. Towards a Europe for All Ages- Promoting Prosperity and Intergenerational Solidarity. Brussels: Commission of the European Communities; 1999. COM (1999) 221.

3. Rehm J, Room R, Monteiro M, Gmel G, Graham K, Rehn N, et al. Alcohol Use. In: Ezzati M, Lopez AD, Rodgers A, and Murray CJL. Comparative quantification of health risks: Global and regional burden of disease due to selected major risk factors. Geneva: WHO; 2004

4. Anderson P, Baumberg B. Alcohol in Europe. London: Institute of Alcohol Studies; 2006. http://dx.doi.org/10.1080/09687630600902477

5. Hallgren M, Högberg P, Andréasson S. Alcohol consumption among elderly European Union citizens Health effects, consumption trends and related issues. Expert Conference on Alcohol

\section{Acknowledgements}

The VINTAGE project Good Health into Older Age is a project funded by the Executive Agency for Health and Consumers, under the European Commission Second Programme of Community Action in the Field of Health 2008-2013 (Grant Agreement no. 20081203). We particularly wish to thank Gino Farchi and Mats Halgren who reviewed the VINTAGE reports, and Ann Hope acting as independent evaluator of the whole project.

We are considerably indebted to many colleagues who have provided advice and support and to the many people who promptly answered to our queries and participated in the survey or provided their unpublished work. Finally, a special thank to Rosaria Russo for the technical and administrative support and collaboration given to the working team, and to Pierfrancesco Barbariol and Lorenzo Fantozzi for the time spent on the creation and management of the VINTAGE website www.epicentro.iss.it/vintage.

\section{Conflict of interest statement}

There are no potential conflicts of interest or any financial or personal relationships with other people or organizations that could inappropriately bias conduct and findings of this study.

\section{Appendix}

The components of the VINTAGE project Working Group are: Emanuele Scafato (Project Leader), Lucia Galluzzo (Project Coordinator) - Centro Nazionale di Epidemiologia, Sorveglianza e Promozione della Salute, Istituto Superiore di Sanità, Rome, Italy; Peter Anderson, Onno Van Schayck - Faculty of Health, Medicine and Life Sciences, Maastricht University, The Netherlands; Joan Colom, Lidia Segura, Jorge Palacio-Vieira Department of Health, Program on Substance Abuse, Government of Catalonia, Barcelona, Spain; Andrew McNeill - Institute of Alcohol Studies, Huntingdon, United Kingdom; Sandra Radoš Krnel - Research Centre, Institute of Public Health, Ljubljana, Slovenia; Salme Ahlström, Esa Osterberg - National Institute for Health and Welfare, Helsinki, Finland; Hana Sovinova Coordination, Monitoring and Research Unit, National Institute of Public Health, Praha, Czech Republic; Claudia Gandin, Silvia Ghirini, Sonia Martire, Alessandra Rossi, Lucilla Di Pasquale Centro Nazionale di Epidemiologia, Sorveglianza e Promozione della Salute, Istituto Superiore di Sanità, Rome, Italy.

Submitted on invitation. Accepted on 30 May 2012. and Health 2009, Sep 21-22; Stockholm, Sweden. Stockholm: Swedish National Institute of Public Health; 2009.

6. Beresford TP. Alcoholic elderly: Prevalence, screening, diagnosis, and prognosis. In: Beresford T, Gomberg E. Alcohol and aging. New York: Oxford University Press; 1995.

7. Hallgren M, Högberg P, Andréasson S. Alcohol consumption and harm among elderly Europeans: falling between the cracks. Eur J Public Health 2010;20:616-7. http://dx.doi.org/10.1093/eurpub/ckq111

8. O'Connell H, Chin AV, Cunningham C, Lawlor B. Alcohol use disorders in elderly people - redefining an age old problem in old age. $\mathrm{Br}$ Med $J$ 2003;327:664-7. http://dx.doi.org/10.1136/bmj.327.7416.664

9. Council of the European Union. Council conclusions on healthy and dignified ageing. $2980^{\text {th }}$ employment, social policy, health and consumer affairs. Council meeting Brussels 30 November 2009. Brussels: Council of the European Union; 2009. Available from: www.epha.org/IMG/pdf/ Council_Conclusion_on_Healthy_and_Dignified_Ageing.pdf. 
10. Scafato E. Alcohol and the elderly: the time to act is now! Eur J Public Health 2010;20:617-8. http://dx.doi.org/10.1093/eurpub/ckq112

11. Focus on Alcohol Safe Environment (FASE). [Internet]. Utrecht: European Commission Project; 2007. [cited 2012 jul 23]. Available from: www.faseproject.eu/wwwfaseprojecteu/home/home.html.

12. Sorocco KH, Ferrell SW. Alcohol use among older adults. $J$ Gen Psychol 2006;133:453-67.

http://dx.doi.org/10.3200/GENP.133.4.453-467
13. Reid MC, Boutros NN, O'Connor PG, Cadariu A, Concato J. The health related effects of alcohol use in older persons: a systematic review. Substance Abuse 2002;23:149-64. http://dx.doi.org/10.1080/08897070209511485

14. Moore AA, Whiteman EJ, Ward KT. Risks of combined alcohol/medication use in older adults. Am $J$ Geriatr Pharmacother 2007;5:64-74.

http://dx.doi.org/10.1016/j.amjopharm.2007.03.006

15. Loukissa D. Under diagnosis of alcohol misuse in the older adult population. Br J Nurs 2007;16:1254-58. 